From the result described hero, it is suggested that chromomyein $A_{3}$ selectively inhibits the biosynthesis of RNA in mammalian cells. It is interesting to note that this agent selectively inhibits biosynthesis of RNA and permits formation of DNA to proceed. This is in contrast to other antitumour substances, such as alkylating agents and mitomycin $C$, which selectively inhibit biosynthesis of DNA. Further work on the mode of action of chromomycin $A_{3}$ are now in progress using various labelled precursors of nucleic acid.

We thank Prof. O. Hayaishi and Assistant Prof. Y. Sugino for their advice and for facilities.

G. WAKISAKA
H. UCHINO
T. NAKAMURA
H. SOTOBAYASHI
S. SHIHAKAWA
A. ADACHI
M. SAKURAI

Depærtment of Internal Medicine, Kyoto University, Japณn.

${ }^{1}$ Sato, K., Okamura, N., Utagawa, K., Ito, Y., and Watanabe, M., Sci. Rep. Res. Inst. Tohoku Vniv., C, 8, 224 (1960)

${ }^{2}$ Kajiwara, T., Watanabe, J., Yoneda, T., and Usui, T., Ann. Rep. Takeda Res. lab., 19, 68 (1960).

${ }^{3}$ Hecht, I. I., and Potter, V. R., Cancer Res., 16, 988 (1956).

- Skoog, W. A., and Beck, W. S., Blood, 11, 436 (1956).

\section{Synthesis of Naphthotocopherol}

THE method of Tishler et al. ${ }^{1}$ for the synthesis of naphthotocopherol consistently yielded a product contaminated with as much as 5 per cent of naphthotocopheryl acetate. The contaminant was detected by infrared spectroscopy and was isolated by thin-layer chromatography ${ }^{2}$. Since thin-layer chromatographic purification was not suitable for preparing sufficient quantities of the naphthotocopherol for investigations in biological systems, the method reported here was developed.

Compounds similar to the tocopherols, and specifically naphthotocopherol, have been suggested as possible intormediates in the chemical reactions leading to the formation of adenosine triphosphate by mitochondrial electron transport ${ }^{3-5}$. Recently, Brodie ${ }^{6}$ has also reported that a naphthotocopherol-like intermediate has been isolated from a bacterial system capable of carrying out oxidative phosphorylation. In our work on the phosphorylation mechanism, the contamination found in the original synthetic naphthotocopherol caused a number of difficulties in the synthesis of derivatives postulated as intermediates in these reactions ${ }^{5}$. The ester contaminant in many instances could not be separatcd from the products when naphthotocopherol was the starting matorial and consequently led to erroneous results when synthetic compounds were studied in various mitochondrial systems.

The procedure reported here utilizes $p$-dioxane instead of acetic acid as the reaction medium. Thero are two advantages in this; (1) it avoids ester formation; (2) it serves as a solvent for the reactants and products rathor than as at suspending medium.

A solution of $5 \cdot 0 \mathrm{~g}$ of phylloquinone (2-methyl-3-phytyl1,4-naphthoquinone), $10.0 \mathrm{~g}$ of stannous chloride and $5 \cdot 0$ ml. concentrated hydrochloric acid in $50.0 \mathrm{ml}$. of $p$-dioxane was refluxed for $6 \mathrm{~h}$. The hot solution was decanted on to $50 \mathrm{~g}$ crushed ice, and extracted twice with $50 \mathrm{ml}$. ethor. After washing the ethereal laycr three times with water, three times with $5 \cdot 0$ per cont aqueous bicarbonate solution and again with water, it was dried over anhydrous sodium sulphate. A pale, yellow, oily liquid was obtained after the ether was removed by cvaporation, using a rotary vacuum ovaporator. The oily product was purified by passing three times successively through $36 \mathrm{~cm} \times 3 \mathrm{~cm}$ columns containing $50 \mathrm{~g}$ of 4 per cent water-deactivated silicic acid, using chloroform as solvent. After removal of the chloro- form the product was obtained as a pale straw-coloured viscous liquid. The yield was 90 per cent of starting matorial (when rofluxed for only $4 \mathrm{~h}$, the yield was 82 per cent).

Anal. calculation for $\mathrm{C}_{31} \mathrm{H}_{48} \mathrm{O}_{2}: \mathrm{C}, 82 \cdot 24, \mathrm{H}, 10 \cdot 68$ found: $\mathrm{C}, 81 \cdot 88, \mathrm{H}, 10 \cdot 67 ; \mathrm{C}, 81 \cdot 89, \mathrm{H}, 10 \cdot 46$.

In cyclohexane the compound shows $\lambda_{\max }$ at 248,322 , and $366 \mathrm{~m} \mu$ and an $\varepsilon$ value ior the 248 maximum of 2.66 $\times 10^{4}$. This spectrum is idontical with that reported by Tishler et al. ${ }^{1}$ except that the absorption maximum for their major peak was $245 \mathrm{~m} \mu$. The infra-red spectrum of the compound in chloroform shows $a_{0}$ characteristic phenolic hydroxyl group frequency at $2,850 \mathrm{~cm}^{-1}$, the ether linkage of the chroman ring at 1,080 and $1,040 \mathrm{~cm}^{-1}$ and no frequencies indicating the presence of quinone. The infra-red spectra of the two products are identical with the exception that tho product obtained using acetic acid ${ }^{1}$ shows a peak at $1,730 \mathrm{~cm}^{-1}$, due to the accompanying ester group.

We thank Drs. C. H. Jarboe and J. F. Taylor for their advice. This work was supported in part by the National Science Foundation $(G-1157)$ and the United States Public Health Service $(H-2102 C)$, and was done while one of us (R. D. D.) was an established investigator of the American Heart Association.

Jinda H. Chen

R. Duncan Dallam

Department of Biochemistry,

University of Louisville School of Medicine, Louisville, Kentucky.

${ }^{1}$ Tishler, M., Fieser, L. F., and Wendler, N. L., J. Amer. Chem. Soc., 62, $1982(1940)$.

${ }^{2}$ Stahl, E., Chem. Z., 82, 323 (1958).

' Dallam, R. D., and 'Laylor, J. F, Fed. Proc, 18, 826 (1959).

4 Slater, E. C., Proc. Fourth Intern. Congr. Biochem.,11, 316 (Pergamon Press, London, 1960).

${ }^{5}$ Dallam, R, D., Biochem. and Biophys. Res. Comm., 4, 106 (1961).

Brodie, A. F., Fet. Proc., 20, 995 (1961).

\section{Inhibition of Lactic Dehydrogenase Isoenzymes}

THE enzymo lactic dehydrogonase has rocently been shown to exist in several molecular forms, which are capable of differentiation by a variety of techniques. Working with both serum and tissues, it has been possible to demonstrate by column chromatography ${ }^{1}$, use of DPN analoguos ${ }^{2}$, starch-gol ${ }^{3,4}$ and agar-gel ${ }^{5-7}$ electrophoresis, that at least 5 typos of lactic dohydrogenaso oxist. These isoenzymes, which show the electrophoretic mobility of the globulins, have been classified with their tissue sourco as follows:

Lactic dehydrogenase of $\alpha_{1}$ mobility is derived from hoart muscle; luctic dehydrogenase of $\alpha_{2}$ and $\alpha_{1}$ mobility is derived from rod blood cells and skeletal muscle; lactic dehydrogenase of $\gamma$ mobility is derived from liver and malignant cells.

These methods of separation have boen utilized to demonstrate the source of increased serum lactic dehydrogenase activity which occurs in many disease states. It has been shown that heart lactic dehydrogenase is the component elevated in myocardial infaretion ${ }^{6-8}$, whero serum lactic dehydrogenase levels are raised, and remain high for several days following infarction ${ }^{10-12}$, while measurement of lactic dehydrogenase showing a $\gamma$ mobility has been suggested as an index of liver damage ${ }^{13}$. There is obviously a useful clinical application for these techniques, limited somewhat by the complexity of the methods, despite attempts at simplification ${ }^{7,14}$.

With the view of producing a simpler test based on selective inhibition of one or more of the isoenzymes, the inhibitory properties of soveral compounds wero investigated. Some attempts along these lines have already been made, and it has been shown that there is a different response among the scrum lactic dehydrogenase isoenzymes to the inhibitory effect of heat ${ }^{15}$. It has 